$\underline{\text { Three Minute Article for Parents }}$

\title{
Exposure to agro-chemicals and occurrence of allergic diseases in children
}

\author{
S T Kudagammana (iD 0000-0002-5813-5907, Keerthi Mohotti iD 0000-0001-6247-0348
}

Sri Lanka Journal of Child Health, 2019; 48(3): 279

DOI: http://dx.doi.org/10.4038/sljch.v48i3.8772

(Key words: Exposure to agrochemicals, allergic disease, children)

\begin{abstract}
Allergic diseases are a common group of illnesses among children and are increasing in prevalence. The International Study of Asthma and Allergy in Children showed $27 \%$ of Sri Lankan children of the 6 to 7 year age group to have had wheezing over the preceding 12 months. The common allergic diseases are asthma (characterized by recurrent wheezing), allergic rhinitis (characterized by nasal symptoms such as discharge from or blockage of the nose, in the absence of infection), eczema (characterized by persistent thickened itchy skin rash) and food allergies. A child can have one or more of these conditions at the same time or at different times of his or her life.
\end{abstract}

The reason for some children getting allergic diseases and for not getting get them is not very clear. It is recognized that there is a genetic predisposition and in the presence of certain triggering environmental factors, these children may develop allergic diseases. Exposure to smoke during pregnancy, pre-natal exposure to viral infections, repeated courses of antibiotics and paracetamol, have been proven to be risk factors while breast feeding has been shown to be protective against allergies. Exposure to agro-chemicals is postulated to cause allergic diseases but some studies have shown it to be against this contention.

Our study was conducted on pre-school children living in two tea estates of the hill country of Sri Lanka, one using conventional agricultural practices and the other using organic practices ${ }^{1}$. The organic estate in Haputale has not used any artificial fertilizer or pesticide for the last 25 years. The other estate in Talawakelle, used a conventional system which includes spraying of weedicides, fungicides, pesticides and use of chemical fertilizer. Due to outward behaviour of children and due to the closeness of the environment they live in, the children get significantly exposed to these chemicals. Data of a total of 81 pre-school children in the Haputale estate (Organic estate) and 118 preschool children in the Talawakelle estate (conventional estate) were analysed. Out of them, $41.2 \%$ and $59.8 \%$ had wheezing respectively in the two estates. Percentages of allergic rhinitis were as $37.7 \%$ and $82.5 \%$, and eczema was $17.5 \%$ and $20.28 \%$ respectively. This showed significantly higher occurrence of allergic diseases in the children living in the conventional estate.

Hygiene hypothesis suggests that the cleaner environments lead to reduced exposure to infections and infestations leading to more allergies. Pesticides are also anti-microbial so that an environment with agro-chemicals makes a "cleaner environment", which predisposes to more allergies. This can explain the higher prevalence of allergic diseases in the conventional estate. The study highlights another reason, among many others, as to why stringent policies should be adopted in using agro-chemicals and artificial fertilizer in agriculture.

\section{Reference}

Environmental exposure to agrochemicals and allergic diseases in preschool children in high grown tea plantations of Sri Lanka. Sanath Thushara Kudagammana, Keerthi Mohotti. Allergy, Asthma \& Clinical Immunology December 2018, 14:84. https://doi.org/10.1186/s13223-018-0308-z 